Diabetologia $9,25-29(1973)$

(c) by Springer-Verlag 1973

\title{
Indirect Measurement of Systolic Blood Pressure by Strain Gauge Technique at Finger, Ankle and Toe in Diabetic Patients without Symptoms of Occlusive Arte.ial Disease
}

\author{
P.E. Nielsen and S. Munkgaard Rasmussen \\ Medical Dept. C, Dept. of Clinical Physiology and X-ray Dept. II, Bispebjerg Hospital, Copenhagen NV, Denmark
}

Received: August 11, 1972

Summary. The systolic blood pressure has been measured at the first finger, ankle and first toe, using the strain gauge technique, in 22 diabetic patients aged 40 to 59 years, with diabotes of 11 to 42 years duration, and in 14 non-diabetics in the same age group - all without clinical evidence of occlusive arterial disease in the legs and with palpable pulses in the feet. - The mean systolic gradients (arm-finger, arm-ankle, arm-toe) were equal in the dia. betics and nondiabetics. Using mean $\pm 2.5 \times$ S.D. as normal limits, a significantly elevated systolic blood pres- sure at the given sites was found in 12 observations among 6 diabotics; 5 of these patients had arterial calcification shown by radiography. In only one observation, a significant pressure drop suggesting artorial stenosis was demonstrated.

Key words: Blood pressure determination, systolic blood pressure, diabetic angiopathy, periphoral vascular discase, strain gauge plethysmography, pulse wave velocity, Mönckebergs sclerosis.
The classical method of indirect blood pressure measurement based on external compression and distal pulse registration is currently being applied to the lower extremities with the aim of diagnosing arterial disease (Strandness et al., 1961 ; Gundersen, 1971 ; Las. sen et al., 1972; Nielsen et al., 1972; Carter, 1968). Diabetic patients with arterial disease of the legs tend to a more distal location of the arterial occlusion than non-diabetics (Strandness et al., 1964; Edwards, 1959; Carnazzo et al., 1966; Conrad, 1967). In the present study the distal pressure measurement has been applied to a group of long term diabetics without clinical symptons of occlusive arterial disease to see if subclinical cases of distal occlusions, manifested by low distal pressure, would be frequently discovered. The investigation also aimed at disclosing arterial wall stiffness as manifested by noncompressibility of the leg arteries (falsely high distal pressure).

\section{Material and Method}

22 insulin treated diabetics $(14$ females, 8 mailes, mean age 49) with known diabetes of 11 to 42 years duration (mean 22 years) were compared to 14 non-diabetics (5 females, 9 males) aged 43 to $\tilde{57}$ years (mean 48 years) all without intormittent claudication and with normal pulses in the feet. The diabetic patients had varying degrees of diabetic angiopathy. Retinopathy was present in 15 of the 22 patients; 4 had nephropathy (elevation of serum creatinine and/or proteinuria) and 1 of the patients had a prior coronary occlusion.

The following parameters were investigated:

1. Double measurements of the systolic blood pressure at the first finger, ankle and first toe on both sides using tho strain gauge technique as furthor described in an earlier publication (Nielsen et al., 1972). The occluding cuffs were placed around the ankle region $(12 \times 26 \mathrm{~cm}$ cuff $)$ or around the proximal phalanges of the first toe $(2.4 \times 9 \mathrm{~cm}$ cuff) and the strain gauges wero placed around the distal phalanx of the first toe. In measurement of the systolic finger pressure the cuffs were similarly placed around the proximal part of the first finger and the strain gauge on the distal part. The blood pressure in the right arm was measured simultaneously by another observer using the standard auscultatory method. The mean of the double measurements was used in the calculations.

2. Pulse wave velocity measured in the supine position: With strain gauges placed around the proximai phalanges the pulse curves in finger and toe were recorded simultaneously using maximal amplification. The paper speed was $10 \mathrm{~cm}$ per second (Fig. 1). From 5 pairs of correspond. ing pulse curves the time interval of the ascending part of the pulse curves betweon finger and toe was measured with $0.5 \mathrm{~mm}$ accuracy. With hand and arm stretched along the body, the distance between the two strain gauges was measured. The pulse wave velocity ( $m$ per second) was taken as the distance between the two strain gauges $(\mathrm{cm})$ divided by the average delay of the pulse curve $(\mathrm{mm})$

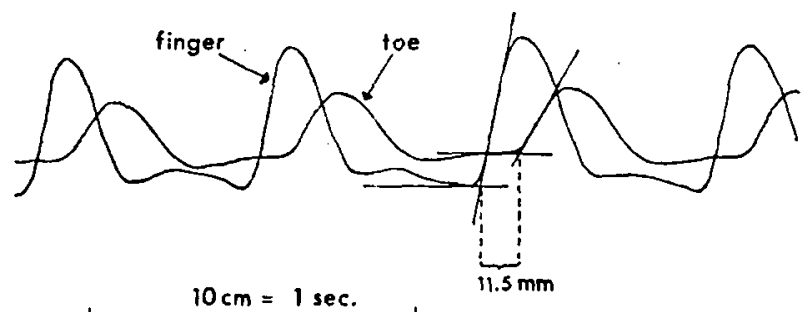

Fig. 1. Pulse curves from the first finger and the first toe recorded simultaneously with strain gauges placed at the middle of the proximal phalanges in a $5 \tilde{5}$ years old man. The delay in time between the ascending parts of the two pulse curves is used to determine tho pulse wave velocity (see the text)

3. In the diabetics the degree of calcification in the arterial walls was estimated in X-rav investigations of the ankle regions and feet. Pronounced calcification: calcification could be scen in the whole lenght of the arteries at the ankle region. Slight calcification: few or single plaques of calcification could bc seen in the arterial wall. 


\section{Results}

A. Relation between the systolic finger, ankle and toe pressure and the arm pressure

The mean systolic pressure differences between the fingers, ankles and toes and the corresponding arm
mmHg higher than the arm pressure in the diabetic and non-diabetic groups, and the systolic toe pressure respectively -4.3 and $-9.7 \mathrm{mmHg}$ below the systolic arm pressure. However, there was a much bigger scatter in the diabetic group compared to the nondiabetics and the standard deviations in the diabetic

Tablo 1. The mean difference between the systolic blood pressure measured at the finger, ankle and toe by the strain gange technique and systolic arm pressure measured by auscultation in 22 diabetics with diabetes of more than 10 years duration compared to 11 non-diabetics - all without clinical evidence of peripheral arterial disease

\begin{tabular}{|c|c|c|c|c|c|c|}
\hline- & & $\begin{array}{l}\Delta \text { finger-arm } \\
\text { pressure } \\
(\mathrm{mm} \mathrm{Hg})\end{array}$ & $\begin{array}{l}\Delta \text { ankle-arm } \\
\text { pressure } \\
(\mathrm{mm} \mathrm{Hg})\end{array}$ & $\begin{array}{l}\Delta \text { toe-arm } \\
\text { pressure } \\
(\mathrm{mm} \mathrm{Hg})\end{array}$ & $\begin{array}{l}\text { ankle-toe } \\
\text { gradient } \\
\text { (corrected for } \\
\text { change in } \\
\text { systolic arm } \\
\text { pressure } \\
\text { (mm Hg) }\end{array}$ & $\begin{array}{l}\text { pulse wave } \\
\text { velocity }\end{array}$ \\
\hline $\begin{array}{l}\text { Diabetics } \\
(n=22 \times 2)\end{array}$ & $\begin{array}{l}\text { mean } \\
\text { S.D. }\end{array}$ & $+\begin{array}{r}1.6 \\
11.2\end{array}$ & $\begin{array}{r}+24.2 \\
16.8\end{array}$ & $\begin{array}{r}4.3 \\
21.0\end{array}$ & $\begin{array}{r}+29.1 \\
22.1\end{array}$ & $\begin{array}{l}9.8 \\
1.6\end{array}$ \\
\hline $\begin{array}{l}\text { Non-diabetics } \\
(n=14 \times 2)\end{array}$ & $\begin{array}{l}\text { mean } \\
\text { S.D. }\end{array}$ & $\begin{array}{r}0.5 \\
6.6\end{array}$ & $\begin{array}{r}+23.6 \\
9.5\end{array}$ & $\begin{array}{r}9.7 \\
10.7\end{array}$ & $\begin{array}{r}+33.3 \\
12.1\end{array}$ & $\begin{array}{l}8.6 \\
1.1\end{array}$ \\
\hline $\begin{array}{l}\text { Normal limits } \\
(\text { mean } \pm 2.5 \times \text { S.D. })\end{array}$ & & $\begin{array}{l}-17-+16 \\
\text { F-tost: } 2.9 \\
P<0.01\end{array}$ & $\begin{array}{l}-1-+58 \\
\text { F-test: } 3.2 \\
P<0.01\end{array}$ & $\begin{array}{l}-37-+17 \\
\text { F-test }: 3.9 \\
P<0.01\end{array}$ & $\begin{array}{l}+3-+63 \\
\text { F-test: } 3.4 \\
P<0.01\end{array}$ & $\begin{array}{l}5.8-11.4 \\
\mathrm{~T} \text {-test : } 3.8 \\
P<0.001\end{array}$ \\
\hline
\end{tabular}

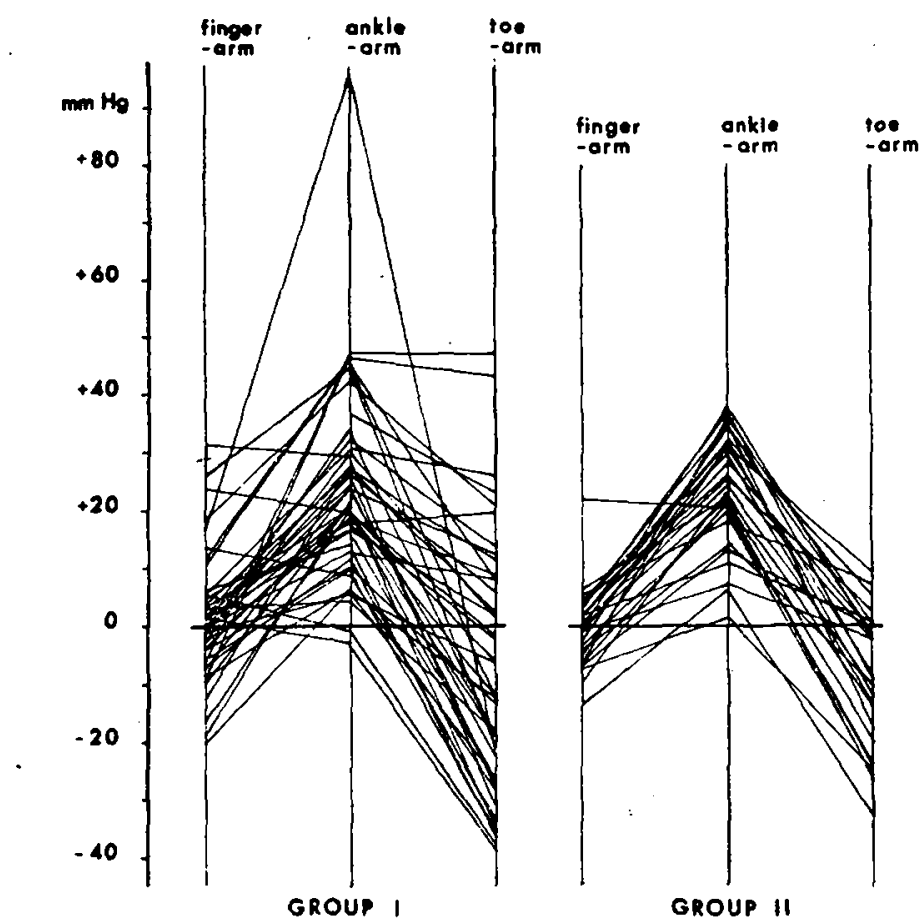

Fig. 2. The systolic blood pressure at the finger, ankle and toe moasured by the strain gauge technique compared to the systolic arm pressure measured by auscultation in 22 diabetics (Group I) and 14 non-diabetics (Group II) with palpable pulses in both dorsal pedal arteries and posterior tibial arteries

pressure for the 22 diabetics and the 14 non-diabetics were compared: there was no statistically significant difference between the two groups (Table 1, Fig. 2). In both groups the average systolic finger pressure equalled the systolic arm pressure. The systolic ankle pressure was on average $+24.2 \mathrm{mmHg}$ and +23.5 group are nearly double those of the non-diabetics (Table 1). Using mean $\pm 2.5 \times$ S.D. as normal limits (Table 1), it will be seen from Fig. 2 that the systolic finger blood pressure in 5 measurements among 3 diabetics was higher than the upper normal limit (16 mmHg above the systolic arm pressure). Similarly, the 
systolic ankle pressure was above the normal limit in 1 observation and the systolic toe pressure above the normal limit in 6 observations in 4 diabetics. Observations below the normal limits were only recorded in one leg. The systolic ankle pressure was, in this patient, $3 \mathrm{mmHg}$ below that of the arm.

\section{B. Ankle-toe gradient}

The drop in systolic pressure from ankle to toe was $29.1 \mathrm{mmHg}$ in the diabetics compared to $33.3 \mathrm{mmHg}$ in the non-diabetics (Table 1), again the scatter being greatest in the diabetic group. The mean drop in pressure in the 10 patients with diabetes of more than 20 years duration was $30 \mathrm{mmHg}$, compared to $28 \mathrm{mmHg}$ in the remaining 12 diabetics.

\section{Pulse wave velocity}

The pulse wave velocity in the diabetic group was significantly higher than in the non-diabetic group (Table 1). Systolic arm pressure was on average higher in the diabetic group than in the non-diabetic (134.3 and $120.8 \mathrm{mmHg}$ respectively), and a correlation be. tween the systolic blood pressure and the pulse wave velocity could be demonstrated in the diabetic group $(r=0.64, p<0.01)$. When excluding the 8 diabetics with systolic arm pressures higher than the upper range among non-diabetics $(140 \mathrm{mmHg})$, it was found that the pulse wave velocity was on average $9.1 \mathrm{~m}$ per second in the diabetics compared to $8.6 \mathrm{~m}$ per second in the non-diabetics.

\section{Calcification of the arteries}

Pronounced arterial calcification in the whole length of the arteries in the ankle regions on both sides was found in 4 diabetics and a few plaques with calcification were found in 4 diabetics. The arterial calcification in the first mentioned patients could also be dem. onstrated in the digital arteries of the first toes, although not in the whole length of these arteries.

The indirectly measured systolic ankle pressure was not influenced by the slight calcification with few plaques in the arterial wall, but the 4 patients with pronounced calcification all had quite high recorded ankle pressures, from 18 to $95 \mathrm{mmHg}$ above the systolic arm pressure (Fig. 3). In a total of 12 observations (5 finger, 1 ankle, 6 toe) among 6 diabetics, with measurements above the upper normal limit (mean \pm $2.5 \times$ S.D.), pronounced arterial calcification at the ankle region was demonstrated in 3 of the diabetics and slight calcification in 2.

The highest recorded pulse wave velocity $(16.2 \mathrm{~m} /$ sec) was found in one of the patients with pronounced arterial calcification, but this patient had quite high systolic arm pressure $(180 \mathrm{mmHg})$.

In a preliminary observation, we found in a 59 years old diabetic patient with gangrene of the first toe, but with normal arteriograms of the legs, that the arteries neither at the ankle regions nor at the calves could be occluded, even with cuffs blown up to 300
$\mathrm{mmHg}$, which was $140 \mathrm{mmHg}$ higher than the systolic arm pressure. In this case pronounced arterial calcification was demonstrated in the $\mathrm{X}$-ray investigation.

\section{Discussion}

We have investigated the possibility of finding early manifestations of peripheral arterial disease in diabetics using the sensitive strain gauge technique to measure the systolic blood pressure, but our measurements showed no significant differences between the diabetics and the non-diabetics. This is in agreement with the few measurements in diabetic patients, with short duration of diabetes, in the study published by Carter and Lezack (1971).

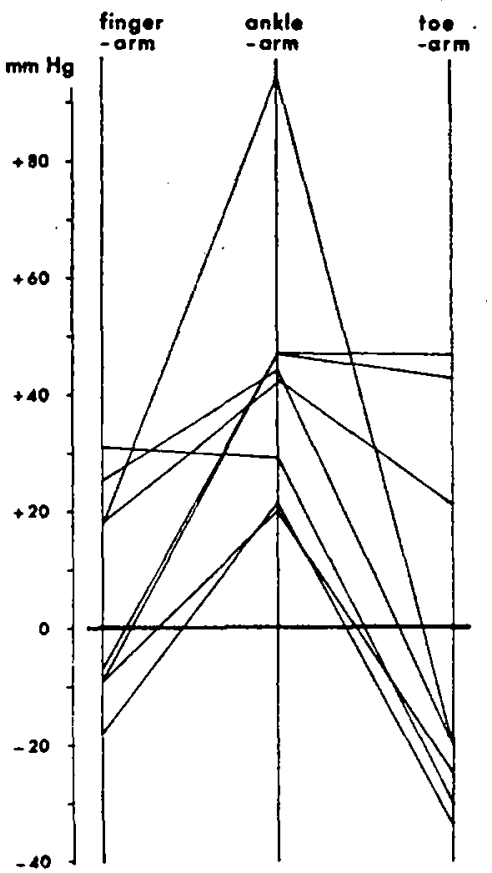

Fig. 3. See legend to Fig. 2. The systolic pressure gradients in the 4 diabetics with pronounced arterial calcification at

the ankle region estimated in $\mathrm{X}$-ray investigation

Falsely high indirect measurements of the systolic blood pressure using occluding cuffs placed around the extremities were, in the present study, correlated with arterial calcification in nearly all the cases. From a theoretical point of view this condition may cause the pressure in arteries with significant stenosis to be recorded as normal or even higher than normal. During the measurements it must be kept in mind that prolonged suprasystolic cuff pressure may cause development of arterial lesions due to crushing of the calcifications.

From investigations in patients with peripheral arterial disease we have demonstrated a good agreement between arterial occlusions, seen on the angio- 
grams, and a drop in systolic blood pressure measured at different levels in the legs (Bell et al., 1973). However, we also found that arterial occlusions in one of the crural arteries were not always related to a drop in systolic pressure, as expressed in low ankle pressure, especially if the occlusion was situated in the anterior tibial artery. Our patients all had palpable pulses in both the dorsal pedal artery and the posterior tibial artery. Only arteriography could have given the real answer concerning arterial stenosis or occlusion, and from our measurements we cannot give any firm conclusion regarding arterial lesions. However, we can conclude that it was impossible to find pressure drops suggesting subclinical arterial lesions in the legs and feet in this group of diabetics.

Only few other investigations concerning early lesions in diabetic patients have been published. Megibow et al. (1953), using microplethysmography, and Weber and Wicht (1962) using plethysmographic registration of the pulse curves from the big toes under maximal dilatation, found frequent involvement of the arteries among the diabetics. However, both investigations were without control material. Munck et al. (1966) and Karlefors (1966) measuring the peak flow after ischaemic exercise, using the 133-Xenon clearance method, found the mean peak flow equal in nondiabetics and diabetics without signs of occlusive arterial disease in the legs. However, Juel Christensen (1968) found a decrease in peak muscle blood flow in diabetics with arterial calcification.

The measurement of the pulse wave velocity as an early indicator of arterial disease in diabetics has been used by Woolam et al. (1962), Schimmler (1968) and Katz (1970). They found increased velocity in the diabetics, which could not be explained by differences in systemic blood pressure, a factor which is known to in. fluence the pulse wave velocity (Hallock (1934), Schimmler (1968), Lyager Nielsen et al. (1968). The pulse wave velocity increases with age probably due to the rise in blood pressure as well as the increasing rigidity of the arterial wall. It is therefore interesting that we could not find any difference between diabetics and non-diabetics, when the two groups with comparable blood pressure were considered.

\section{Conclusion}

The measurement of the systolic blood pressure in the legs using the strain gauge technique is a sensitive and accurate method, which can be used, without discomfort for the patient, in determining arterial lesions. Good agreement between the pressure gradients and occlusions verified by arteriography has been demonstrated earlier, although single occlusion of one of the crural arteries will not always be picked up with the strain gauge measurements. Fspecially in the diabetic patients with frequent involvement of the peripheral arteries, these measurements at the ankle and toe are a good supplement to the clinical examination, giving an objective and reproducible value of the degree of occlusive disease.

The present measurements among long-term diabeties, with special reference to early manifestation of arterial disease, did not show occlusive involvement of the leg arteries, apart from a few falsely high systolic ankle and toe pressures due to arterial calcification.

\section{References}

Bell, G., Nielsen, P.E., Ụlrich, J., Engell, H.C.: The measurement of systolic blood pressure in arteriosclerotic legs using the strain gauge technique. Cardiovasc. Res. in press. (1973).

Carnazzo, A.J., Kelly, G.J., Booth, R. W., Skillman, T. G.: Use of pedal angiography to study diabetic angiopathy. Abstract in Diabetes 15, 525 (1966).

Carter, S.A.: Indirect systolic pressures and pulse waves in arterial occlusive disease of the lower extremities. Circulation 37, 624 (1968).

Carter, S.A. \& Lezack, J.D.: Digital systolic pressures in the lower limb in arterial disease. Circulation 43, 905 (1971).

Edwards, E.A.: Postamputation radiographic evidence for small artery obstruction in arteriosclerosis. Ann. Surg. 150, 177 (1957).

Gundersen, J.: Diagnosis of arterial insufficiency with measurement of blood pressure in fingers and toes. Angiology 22, 191 (1971).

Hallock, P.: Arterial elasticity in man in relation to age as evaluated by the pulse wave velocity method. Arch. intern. Med. 54, 770 (1934).

Conrad, M.: Large and small artery occlusion in diabetics and non-diabetics with severe vascular disease. Circulation 36, 83 (1967).

Juel Christensen, N.: Muscle blood flow, measured by 133-Xenon and vascular calcifications in diabetics. Acta med. scand. 183, 449 (1968).

Karlefors, T.: Circulatory studies in male diabetics, p. 14. Halmstad: Thesis (1966).

Katz, H.P., Cheitlin, M.D., Wasser, A.H., Flair, R.C.: Observations on the pulse wave velocity and tissue biopsy in children with diabetes mellitus. John Hopk. Med. J. 127, 336 (1970).

Lassen, N.A., Tvedegard, E., Jeppesen, F.I., Nielsen, P.E., Bell, G., Gundersen, J.: Distal blood pressure measurement in occlusive arterial disease, strain gauge compared to Xenon-133. Angiology 23, 211 (1972).

Lindbjerg, I.F.: Leg muscle blood-flow measured with 133-Xenon after ischaemia periods and after muscular exercise performed during ischaemia. Clin. Sci. 30, 399 (1966).

Lyager-Nielsen, B., Straede-Nielsen, J., Fabricius, J.: Pressure wave velocity in the human aorta. J. Amer. Geriat. Soc. 16, 647 (1968).

Mendlowitz, M., Grossman, E.B., Alpert S.: Decreased hallucal circulation, an early manifestation of vascular disease in diabetes mellitus. Amer. J. Med. 15, 316 (1953).

Nielsen, P.E., Bell, G., Lassen, N.A.: The measurement of digital systolic blood pressure by strain gauge technique. Scand. J. clin. Lab. Invest. 29, 371 (1972).

Schimmler, W.: Zur Bedeutung der zentralen Pulswellengeschwindigkeit für die Klinik. Cor Vasa 10, 48 (1968).

Strandness, D.E., Radke, H.M., Bell, J.W.: Use of a new simplified plethysmograph in the clinical evaluation of patients with arteriosclerosis obliterans. Surg. Gynec. Obstet. 112, 751 (1961). 
Strandness, D.E., Priost, R. E., Gibbons, G.E.: Combined clinical and pathologic study of diabetic and non-dia. betic peripheral arterial disease. Diabotes 13, 366 (1964).

Weber, H.W., Wicht, C.I.: The poripheral angiopathy of diabetics. S. Afr. J. Lab. clin. Med. 8, 83 (1962).

Woolan, G.L., Schnur, P.L., Vallbona, C., Hoff, H.E.:
The pulse wave velocity as an early indicator of atherosclorosis in diabetic subjects. Circulation 25, 533 (1962).

I)r. Poul Ebbo Nielsen

Iedical Dept. C Bispebjerg Hospital

DK-2400 Copenhagen NV

Denmark 